\title{
Synthesis and Characterization of Nanostructured Blends of Epoxy Resin and Block Copolymers
}

\author{
Rajesh Pandit ${ }^{1,2,3}$, Albrecht Berkessel ${ }^{4}$, Ralf Lach ${ }^{5,6}$, \\ Wolfgang Grellmann ${ }^{5,6}$ and Rameshwar Adhikari ${ }^{1,3 *}$ \\ ${ }^{1}$ Tribhuvan University, Central Department of Chemistry \\ Kirtipur, Kathmandu \\ ${ }^{2}$ Department of Chemistry, Tri-Chandra Campus \\ Ghantaghar, Kathmandu \\ ${ }^{3}$ Nepal Polymer Institute (NPI), \\ Kathmandu \\ ${ }^{4}$ University of Cologne, Institute for Organic Chemistry \\ Greinstraße 4, Cologne, Germany \\ ${ }^{5}$ Institut für Polymerwerkstoffe e.V. \\ Institute associated with the University of Applied Science Merseburg \\ Merseburg, Germany \\ ${ }^{6}$ Martin-Luther University Halle-Wittenberg \\ Centre of Engineering, Halle/Saale, Germany \\ e-mail: nepalpolymer@yahoo.com
}

\begin{abstract}
Polystyrene-polybutadiene block copolymers having different molecular architectures were epoxidized by using meta-chloroperoxybenzoic acid (MCPBA). Then, the blends with epoxy resin (diglycidyl ether of bisphenol-A; DGEBA) and their nanocomposites with boehmite and layered silicate nanofiller in presence of methylene dianiline (MDA) as a hardener were prepared. The epoxidized copolymers and the composites were characterized by Fourier transform infrared (FTIR) spectroscopy and microindentation technique. In this way, it was possible to tune the morphology of the nanostructured blends of the epoxy resin using the functionalized block copolymer as the template. The presence of nanostructured morphology was attested by the optical transparency of the blends as well as of the composites with nanofiller. The microhardness properties were improved by the incorporation of the nanoparticles, viz. boehmite and layered silicate.
\end{abstract}

Key words: nanostructures, block copolymer, FTIR spectroscopy, microindentation hardness

\section{Introduction}

Block copolymers are the nanostructured materials in which the nature of phase-separated structures can be dictated by the Flory-Huggins interaction parameter $(\chi)$, degree of polymerization $(N)$, volume fraction of the components $\left(\phi_{V}\right)$ and molecular architecture. On the basis of these parameters, the morphology of block copolymer varies from body centered cube (BCC), hexagonal packed cylinder (Hex), gyroid (G) to lamellar (L) structures (Hamley 1998). The ordered nanostructures in block copolymer are self-assembled in solid state, melt as well as in solution. These structures may be applicable for several useful purposes such as in nanoreactors, nanofilters, nanofoamed membranes etc. These are being studied for applications in microelectronics, combinatorial science and nanotube fabrication (Serrano et al. 2004). Block copolymers are widely used as templates for generating nanostructured epoxy or phenolic resins with long-range order in both uncured and cured states (Serrano et al. 2006).

Epoxy resin is one of the thermosetting materials which play an important role in the field of modern polymeric materials. However, their effective application range 
is limited by their inherent brittleness. Many works have been carried out to improve their physical properties, mainly through the incorporation of flexible elastomeric domains within the brittle epoxy network (Grubbs et al. 2000a). A typical toughness modifier (such as soft butadiene polymer) undergoes phase separation during epoxy curing process, which results in irregular distribution of the micron-scaled butadiene inclusions in the resin. The control over the scale and homogeneity of these inclusions would facilitate and could enable the preparation of useful new thermosetting materials (Grubbs et al. 2000b). One possible pathway for generating self-assembled thermosetting nanostructures is the use of amphiphilic block copolymers, whereby one of the block is miscible and the other immiscible with the epoxy resin (Lipic et al. 1998).

The first nanostructured system found by changing of a network-forming formulation created by a diglycidyl ether of bisphenol A (DGEBA) epoxy resin and an aromatic amine with amphiphilic diblock copolymers such as poly(ethylene oxide)-blockpoly(ethyl ethylene) (PEO-PEE) and poly(ethylene oxide)-block-poly(ethylene-alt-propylene) (PEO-PEP) was studied by Hillmyer et al. (1997). Later, Liu et al. (2009, 2009a \& 2010) have shown that nanostructured PEO-PEP/epoxy resins provide improved fracture toughness depending on their morphology. Recently, Serrano et al. (2004) and Ocando et al. (2010) epoxidized styrene-block-butadiene (SB) or styrene-blockbutadiene-block-styrene (SBS) block copolymers, respectively, as templates for nanostructured thermosets. Serrano et al. (2004) found that the epoxidation procedure improves the miscibility of the copolymers with the epoxy resin. Also the curing behavior and final properties of nanostructured thermosetting systems modified with epoxidized diblock copolymers was studies by Serrano et al. (2007). Interestingly, in the different morphologies obtained, the stiffness of the epoxy matrix was retained, and an increase in toughness was observed for hexagonally-packed cylinders obtained from the functionalized SB modified epoxy blends.

Generally, an aromatic amine is used as the hardener which cures the epoxy functional block copolymer blend. As a result, highly cross-linked thermosetting matrix is formed. Since there are no chemical reactions or ionic interactions between the epoxy resin and functional block copolymer, the epoxy polymerization kinetics is largely unaffected by the presence of block copolymer (Lipic et al. 1998).

The advantages of the block copolymers as a blend component with epoxy resins are extensively studied to improve the fracture toughness (Guo et al. 2001, Kim et al. 2001, Hydro \& Pearson 2007, Liu et al. 2009, 2009a and 2010, Kishi et al. 2011). Thus, the block copolymers have been developed for the use as the chemical compatibilizers with epoxy resins. For this purpose, it should be functionalized by introducing the suitable reactive groups into one of the blocks in order to develop the covalent bonding for epoxy network without the loss of long range order in the resulting blends (Grubs et al. 2000b).

Polystyrene-block-polybutadiene-block-polystyrene (SBS) triblock copolymer is one of the thermoplastic elastomers which act as the vulcanized rubber at ambient temperature (Hsiue \& Yang 1990). Polystyrene (PS) block is immiscible with epoxy resin system whereas the polybutadiene (PB) block is chemically modified to turn it miscible with the epoxy resin system at hand (Grubbs et al. 2000b). For the chemical modification, one of the convenient methods is the epoxidation which inserts oxygen atoms in the double bonds of butadiene block. Recently, convenient methods for the epoxidation of the SBS copolymers have been discussed in literature (Pandit et al. 2012).

In this work, different architectures of styrenebutadiene block copolymers were epoxidized. The epoxidized SBS triblock and SB diblock samples were blended with epoxy resins followed by nanocomposites preparation with boehmite and layered silicate.

\section{Methodology}

\section{Materials}

The polymers used in this work were differently architectured polystyrene-block-polybutadieneblock-polystyrene (SBS) triblock as well as star block copolymers and polystyrene-block-polybutadiene (SB) diblock copolymer. The characteristics of the block copolymers along with their notations are given in Table 1. 
Table 1. Characteristics of block copolymer samples used in this work

\begin{tabular}{llcc}
\hline $\begin{array}{l}\text { Sample } \\
\text { code }\end{array}$ & Architecture & $\begin{array}{c}\text { Butadiene } \\
\text { content (\%) }\end{array}$ & $\begin{array}{c}\text { Molar } \\
\text { mass (g/mol) }\end{array}$ \\
\hline LN7 & SBS triblock & 50 & 91,000 \\
LN8 & SB diblock & 52 & 56,000 \\
STX & (SB)x star block & 70 & 180,000 \\
\hline
\end{tabular}

The polymers were kindly supplied by Kraton Polymers, Houston, TX, USA (Courtesy of Dr. Robert Bening). Analytical grade dichloromethane (99\%), meta-chloroperoxybenzoic acid (MCPBA), sodium bicarbonate $\left(\mathrm{NaHCO}_{3}\right)$, sodium sulphate $\left(\mathrm{Na}_{2} \mathrm{SO}_{4}\right)$, potassium iodide/starch paper, diglycidyl ether of bisphenol-A (DGEBA) and methylene diamine (MDA) were purchased from Sigma-Aldrich Ltd., Germany. The nanoparticles boehmite and layered silicate were supplied by Sasol Chemical (Hamburg, Germany) and Süd-Chemie (Munich, Germany). All chemicals were used without further purification.

Epoxidation of block copolymers

Each block copolymer (BCP) was completely epoxidized following the standard procedure discussed in literatures (Serrano et al. 2004 \& Antonietti et al. 1996). One gram of the BCP was dissolved in 10 millilitre of dichloromethane in 100 millilitre three-necked round bottom flask equipped with a magnetic stirrer, thermometer and maintained under inert atmosphere. Calculated amount of meta-chloroperoxybenzoic acid (MCPBA) was added to the polymer solution. The reaction was carried out at $0{ }^{\circ} \mathrm{C}$ under constant stirring for one and half hours. The completion of the reaction and the excess of the MCPBA were tested by taking one drop of the reaction mixture in the potassium iodide/starch paper. After the completion of reaction, the mixture was filtered and separated out from the residue. The filtrate was extracted with saturated aqueous $\mathrm{NaHCO}_{3}$ solution and was then dried with $\mathrm{Na}_{2} \mathrm{SO}_{4}$ and filtered. The organic portion of the solution was separated and the epoxidized BCP was recovered by separating the solvent (i.e., dichloromethane) in a rotary evaporator. The residue was dried till constant weight.

The epoxidation reaction of the BCP is depicted in Scheme 1 taking SBS triblock copolymer as an example.

\section{Schemes}

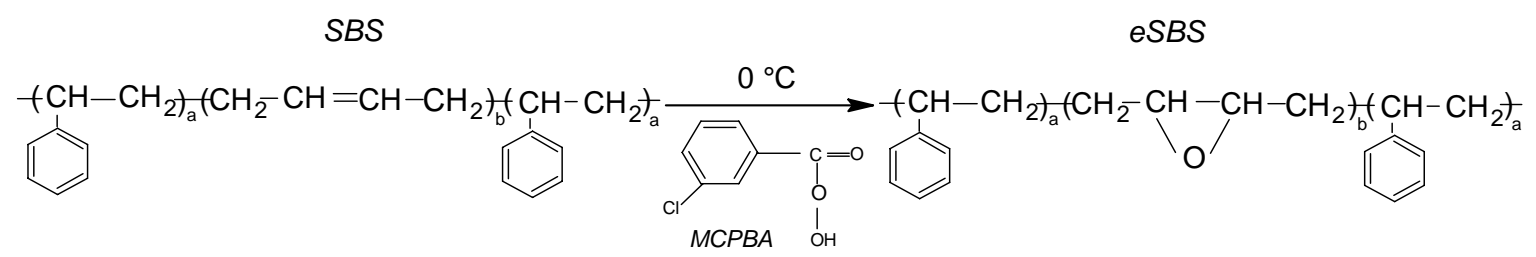

Scheme 1. Scheme of epoxidation reaction of SBS triblock copolymer; the C=C double bonds were changed into the epoxide groups.

The epoxidized samples are denoted by adding the letter " $e$ " before the notation of each sample. For instance, epoxidized versions of samples LN7, LN8 and STX will be denoted by eLN7, eLN8 and eSTX, respectively.

\section{Preparation of blends and nanocomposites}

The neat DGEBA/MDA epoxy system and the blends with epoxidized block copolymers were prepared. In a typical experiment, first, $30 \%$ by mass of epoxidized BCP and $70 \%$ by mass of epoxy resin were dissolved in toluene. The resultant solution was heated up to $110^{\circ} \mathrm{C}$ for complete evaporation of the solvent. Then, calculated amount of the curing agent (i.e., methylene dianiline) was added and heated under constant stirring to make homogeneous mixture. The content was poured into the Teflon mould. For the preparation of nanocomposites, same procedure was repeated by adding 3\% by mass of boehmite (named as OS in this work) and layered silicate (named as LS) separately to the mixture in the required proportion. The blends and nanocomposites were pre-cured in the vacuum oven at $80^{\circ} \mathrm{C}$ for 12 hours followed by post curing at $140^{\circ} \mathrm{C}$ for additional 12 hours. The general nomenclature of the samples is as follows:
A. Resin
Pure epoxy resin hardened and
B. Resin + LS cured,
C. Resin + OS
D. Resin + eLN7 nanofiller, Sample A with boehmite nanofiller, Sample A with epoxidized LN7, 

E. Resin + LS + eLN7 Sample B + sample D (i.e. resin with epoxidized LN7 and layered silicate nanofiller),

F. Resin + OS + eLN7 Sample C + sample D (i.e. resin with epoxidized LN7 and with boehmite nanofiller); and so on.

\section{Spectroscopic characterization}

Fourier transform infrared (FTIR) spectra were recorded in an FTIR Affinity 2000 Spectrometer (Shimadzu corporation) within a wave number range of $600-$ $4000 \mathrm{~cm}^{-1}$.

\section{Microindentation tests}

The microhardness measurements were performed on a Fischerscope H100C recording microhardness testing machine (Helmuth Fischer Co., Germany) equipped with a pyramidal Vickers diamond indenter at room temperature, which was penetrated into the sample with the application of force up to $1000 \mathrm{mN}$.

This technique comprises the continuous measurement of the load applied by an indenter as a function of its penetration depth. In the recent years, more interest has been paid to standardize the methods for analyzing the depth-sensitive data for the micromechanical characterization of the materials. Among these, the most successful method has been introduced in which plastic deformation occurs in loading while upon unloading only the elastic deformation recovers (Lach et al. 2010).

In a typical instrumented microindentation experiment, so called load $(P)$ versus indentation depth $(h)$ curves are recorded. The evaluation of these curves permits the determination of both plastic and elastic works of deformation, different hardness parameters (such as Martens hardness, Vickers hardness, etc.) and the indentation modulus $E_{I T}$ of the samples (Lach et al. 2010 \& Bhandari et al. 2012).

\section{Results and Discussion}

\section{FTIR spectroscopy}

The purpose of the present study is to investigate the influence of molecular architecture of the block copolymer (BCP) on the nanostructure formation of the epoxy/BCP blends. Thus, in this paper, we first analyze the effect of chemical modification of the block copolymers having various architectures on their molecular structure and then apply the functionalized block copolymer in the preparation of the blends and nanocomposites with DGEBA.

The FTIR spectra of different architectures of pure block copolymers (triblock, star block and diblock copolymers, which are designated as LN7, LN8, and STX, respectively, see Table 1) are presented in Fig. 1. The analysis of major peaks located around 910, 966, 1450 and $2918 \mathrm{~cm}^{-1}$ are of particular interest in this work. The peaks around $910 \mathrm{~cm}^{-1}$ and $966 \mathrm{~cm}^{-1}$ represent the vibrations associated with trans- and cis- $\mathrm{C}=\mathrm{C}$ double bonds of 1,4-polybutadiene, respectively. Similarly, the peak around $1450 \mathrm{~cm}^{-1}$ indicates the presence of $\mathrm{CH}$ bending vibrations while that around $2918 \mathrm{~cm}^{-1}$ represents the $\mathrm{CH}$ stretching vibration For all the architectures studied, the FTIR spectra are similar, as expected.

The FTIR spectra of epoxidized samples are presented in Fig. 2. The spectrum of neat LN7 is included for the sake of comparison. Each sample was targeted to 100 $\%$ epoxidation. The following discussion provides evidence to the epoxidation of the block copolymer samples (such as LN7, LN8 and STX, see Table 1).

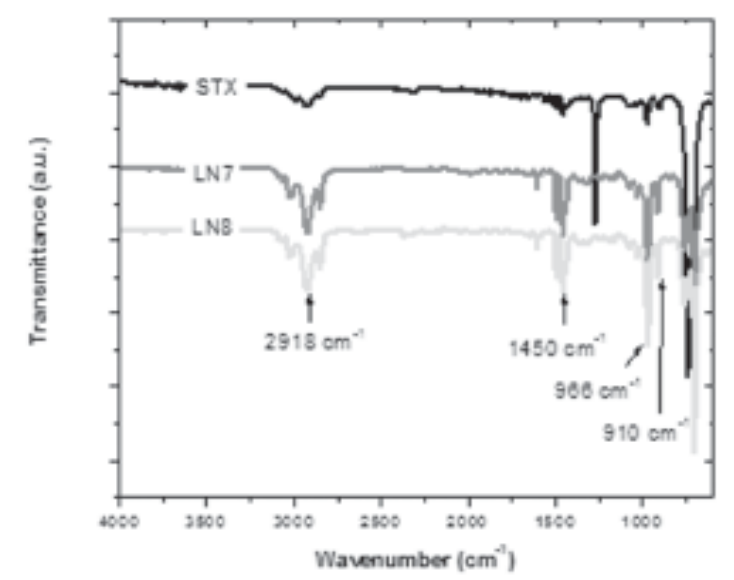

Fig. 1. Fourier transform infrared (FTIR) spectra of different block copolymer samples

The peaks centered around $810 \mathrm{~cm}^{-1}, 889 \mathrm{~cm}^{-1}$ as well as $1215 \mathrm{~cm}^{-1}$ and $1265 \mathrm{~cm}^{-1}$ can be assigned to half epoxy group stretching and whole epoxy ring stretching, respectively. According to some literature works (Hsiue \& Yang 1990), the peaks due to epoxy absorption were found at $810 \mathrm{~cm}^{-1}, 880 \mathrm{~cm}^{-1}, 1270 \mathrm{~cm}^{-}$ ${ }^{1}$ and $1380 \mathrm{~cm}^{-1}$. In addition, the absorption of carbonyl $(\mathrm{C}=\mathrm{O})$ group at about $1700-1740 \mathrm{~cm}^{1}$ and hydroxyl $(\mathrm{OH})$ group at about $3200-3700 \mathrm{~cm}^{-1}$ were found. Similar results were reported by other authors as well 
(Chaisuriyathepul et al. 2008 \& Pandit et al. 2012). They also reported weak absorption peaks at $1725 \mathrm{~cm}^{-1}$ and $3500 \mathrm{~cm}^{-1}$, which represent the presence of carbonyl group $(\mathrm{C}=\mathrm{O})$ and hydroxyl group $(\mathrm{OH})$, respectively. Those observations implied the occurrence of the side reactions during epoxidation of the block copolymers.

In the present work, with the extent of epoxidation in each sample, the intensity of the peak around 966 $\mathrm{cm}^{-1}$ (corresponding to $\mathrm{C}=\mathrm{C}$ bond cis conformation) decreases drastically indicating that the epoxidation reaction preferably occurs at cis positions of the double bonds while the intensity of the peak around $912 \mathrm{~cm}^{-1}$ also changes indicating that the epoxidation reaction has occurred in the double bonds located at the trans positions of 1,4-polybutadiene. The occurrence of the peaks centered around $1246 \mathrm{~cm}^{-1}$ (indicated by an arrow with cross in Fig. 2) implies further the formation of ether (-O-) linkages (see Fig. 2). In summary, it should also be mentioned that the block copolymer architecture played no role on the chemical functionalization of the block copolymer, as expected.

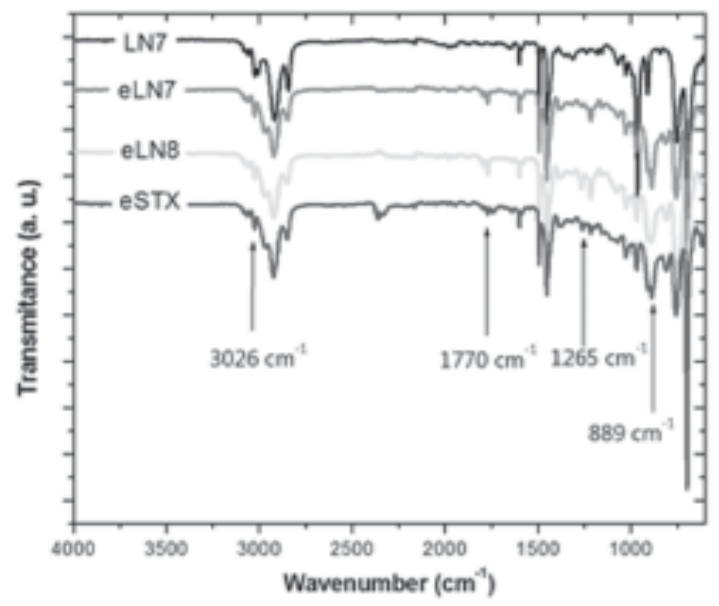

Fig. 2. FTIR spectra of different block copolymer samples after epoxidation compared with that of a linear triblock copolymer LN7

The FTIR studies were extended also to the blends of epoxidized block copolymers of different architectures and epoxy resins as well as to the corresponding nanocomposites. In those cases, only a shift in some of the peaks was observed. After epoxidation of the block copolymers having different architectures to different extents, these were blended with epoxy resins to different proportions. In consistence with the literature works (such as Serrano et al. 2004, Liu et al. 2009, 2009a \& 2010), nanostructured morphologies were observed by transmission electron microscopy (TEM) and X-ray analysis (Adhikari et al. 2012, in preparation).

\section{Microhardness measurements}

In Fig. 3, we present, the load $(P)$-indentation depth (h) diagrams of some of the blends (comprising $30 \%$ by mass of epoxidized BCPs and $70 \%$ by mass of the resin). For the sake of comparison, the curves of the neat copolymer alone and the cured resin are also included in Fig. 3. We present here the discussion of the microindentation properties only qualitatively. First, the hardness (of any kind such as Vickers hardness, Martens hardness, etc.) and indentation modulus are generally correlated; the increase in one property has the consequence of increase of the other. In other words, the hardness and indentation modulus increase or decrease in parallel way.

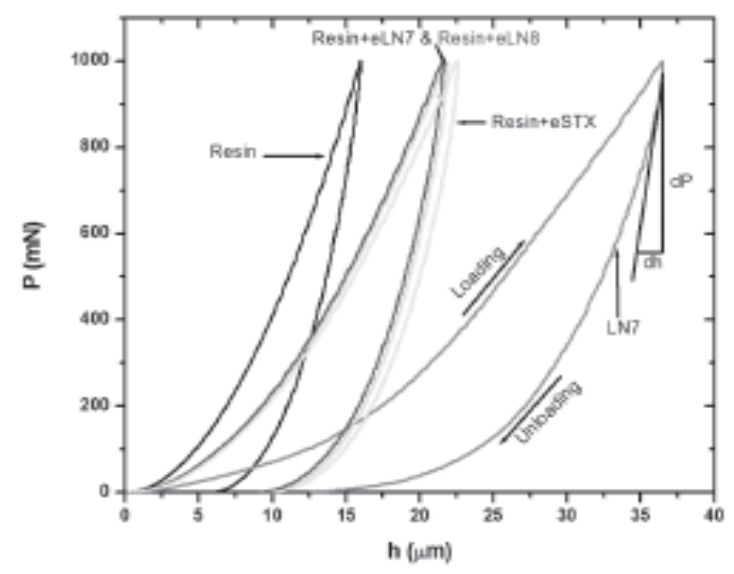

Fig. 3. Load $(P)$-indentation depth $(h)$ diagrams of some of the resins blended with epoxidized block copolymers (eLN7, eLB8 and eSTX) compared with that of neat resin and a neat block copolymer LN7

As introduced in experimental part, the indentation modulus is determined from the slope of initial part of the unloading curve (see Fig. 3: indicated by $\mathrm{d} P / \mathrm{d} h$ for sample LN7 for instance). The lower the magnitude of the slope, the lower will be the value of the indentation modulus, $E_{I T}$ (as well as the hardness value) of the sample. Thus, careful inspection of Fig. 3 reveals that the sample LN7, being the softest material, has the lowest value of $E_{I T}$. The largest value of $E_{I T}$ is possessed by cured resin (see Fig. 3). The indentation 
moduli (and thence the hardness values) of the blends of epoxidized block copolymer and resin fall intermediate between the values of the two samples. Among the blends, the modulus value of the blend of resin with eSTX is the lowest, which can be attributed to the largest rubbery polybutadiene content of the block copolymer STX (see Table 1). The blends (Resin+eLN7) and (Resin+eLN8) have comparable slopes in their unloading curves and hence have comparable moduli and hardness values. It can be concluded that the blending with block copolymer make the resin significantly softer.

Now, the $P-h$ diagrams of resins unmodified and modified with boehmite are compared with that of block copolymer modified resins including boehmite nanoparticles in Fig. 4. One can see that addition of $3 \%$ by mass of boehmite nanofiller causes a significant increase in the slope of the unloading curve of the resin; see Fig. 4. Similarly, the slopes for the block copolymer modified resins are also decreased. Thus,

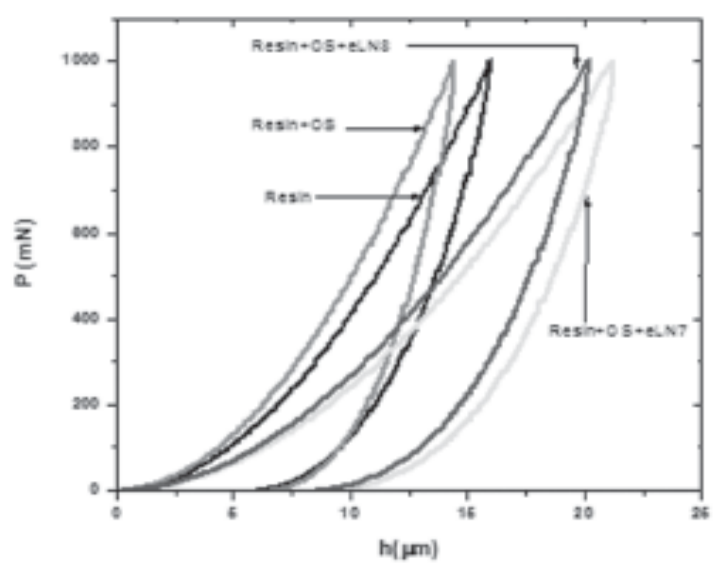

Fig. 4. Load $(P)$-indentation depth $(h)$ diagrams of some of the resins blended with epoxidized block copolymers (eLN7, eLB8) and boehmite nanofiller compared with that of neat resin and the resin with nanofiller

the loss of the moduli and hardness caused by addition of block copolymer is compensated by the addition of small amount of nanofiller. Similar results were obtained for the composites containing layered silicate; see Fig. 5.

In case of the composites comprising layered silicate (LS) nanofiller, some strange phenomena were observed (Fig. 5). For instance, the slope of the unloading curve of the resin with filler was found to decrease, i.e., a loss in modulus and hardness values

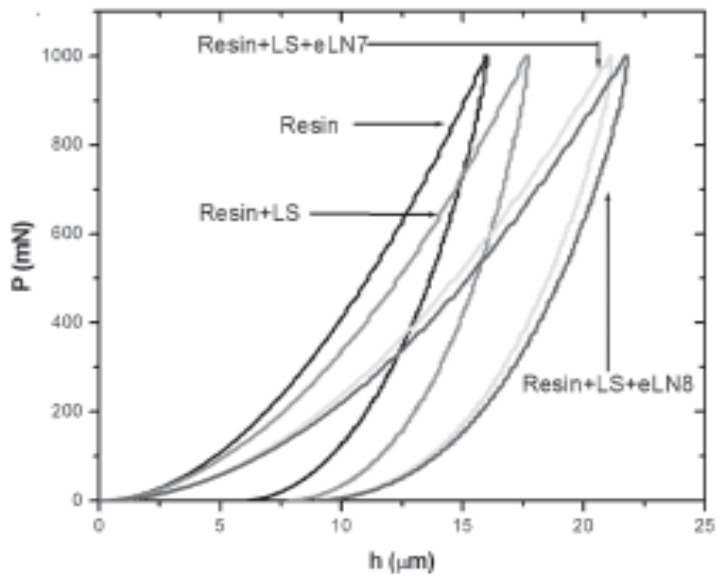

Fig. 5. Load $(P)$-indentation depth $(h)$ diagrams of some of the resins blended with epoxidized block copolymers (eLN7, eLB8) and layered silicate (LS) nanofiller compared with that of neat resin and the resin with nanofiller

which is a surprising observation, because, we expect generally an increase in hardness and indentation modulus due to addition of inorganic filler. It seems that the curing properties of the resin might have been suppressed by the addition of LS leading to the worsening in surface mechanical properties. The exact mechanism, however, should be further investigated.

The block copolymers (BCPs) having different molecular architectures were successfully functionalized by the epoxidation method using MCPBA as the reagent. Further, each epoxidized BCP was blended with epoxy resin with methylene dianiline (MDA) as hardener. Subsequently nanocomposites were prepared using boehmite and layered silicates nanoparticles as filler. The materials were characterized by Fourier transform infrared (FTIR) spectroscopy and microindentation hardness tests. All the blends and composites were optically transparent implying the existence of predominantly nanostructured morphology.

It was found that the surface mechanical properties of the blends as determined by microindentation measurements were found to generally enhance by the incorporation nanoparticles. The epoxidized BCP contributed to increase the toughness of the resin while the nanoparticles contributed to increase their hardness. The nanostructured morphology of the blends and composites should be confirmed by electron microscopic studies in future. 


\section{Acknowledgements}

The authors sincerely thank Kraton Polymers, Houston (TX), Sasol Chemical (Hamburg) and Süd-Chemie (Munich) for the supply of the materials used in this work. R.A. thanks the Alexander von Humboldt Foundation for funding his short research stay in University of Cologne, Germany. R.P. acknowledges University of Cologne, Germany for providing scholarship during his research visit and University Grants Commission for providing Ph.D. research grant. We thank Mr. Sarwar Aziz (Cologne) for his friendly support in the synthetic works.

\section{References}

Adhikari, R., R. Pandit, A. Berkessel, R. Lach, W. Grellmann. 2012. Morphology and deformation behaviour of block copolymer toughened epoxy resin. Polymer (submitted)

Antonietti, M., S. Forster, J. Hartmann and S. Oestreich. 1996. Novel amphiphilic block copolymers by polymer reactions and their use for solubilization of metal salts and metal colloids. Macromolecules 29:3800-3806.

Bhandari, N.L., R. Lach, W. Grellmann and R. Adhikari. 2012. Depth-dependent indentation microhardness studies of different polymer nanocomposites. Macromolecular Symposia 315:44-51.

Chaisuriyathepkul, A., P. Klinpituksa, P. Phinyocheep, C. Nakason and S. Kittipoom. 2008. Synthesis of acrylated styrene-isoprene-styrene copolymer. $e$ Polymers paper no. 141.

Grubbs, R.B., M.E. Broz, J.M. Dean and F.S. Bates. 2000a. Selectively epoxidized polyisoprene-polybutadiene block copolymers. Macromolecules 33:2308-2310.

Grubbs, R.B., J.M. Dean, M.E. Broz and F.S. Bates. 2000b. Reactive block copolymers for modification of thermosetting epoxy. Macromolecules 33:9522-9534.

Guo, Q., P. Figueiredo, R. Thomann and W. Gronski. 2001. Phase behavior, morphology and interfacial structure in thermoset/thermoplastic elastomer blends of poly (propylene glycol)-type epoxy resin and polystyrene$b$-polybutadiene. Polymer 42:10101-10110.

Hamley, I. 1998. The physics of block copolymers. Oxford University Press, London, UK.

Hillmyer, M.A., P.M. Lipic, D.A. Hajduk, K. Almdal and F.S. Bates. 1997. Self-assembly and polymerization of epoxy resin-amphiphilic block copolymer nanocomposites. Journal of American Chemical Society 119:2749-2750.

Hsiue, G.H. and J.M. Yang. 1990. Epoxidation of styrenebutadiene-styrene block copolymer and use for gas permeation. Journal of Polymer Science Part A: Polymer Chemistry 28:3761-3773.

Hydro, R.M. and R.A. Pearson. 2007. Epoxies toughened with triblock copolymers. Journal of Polymer Science Part B: Polymer Physics 45:1470-1481.

Kim, H. R., B.Y. Myoung, K.H. Song, J.I. Yuck and T.H. Yoon. 2001. Toughening of epoxy resin with PESCTBN-PES triblock copolymers. Polymer Korea 25:246-253.

Kishi, H., Y. Kunimitsu, J. Imade, S. Oshita, Y. Morishita and M. Asada. 2011. Nano-phase structures and mechanical properties of epoxy/acryl triblock copolymer alloys. Polymer 52:760-768.

Lach, R., G.H. Michler and W. Grellmann. 2010. Microstructure and indentation behaviour of polyhedral oligomeric silsesquioxanes-modified thermoplastic polyurethane nanocomposites. Macromolecular Materials and Engineering 295:484-491.

Lipic, P.M., F.S. Bates and M.A. Hillmyer. 1998. Nanostructured thermosets from self-assembled amphiphilic block copolymer/epoxy resin mixtures. Journal American Chemical Society 120:8963-8970.

Liu, J., H.-J. Sue, Z.J. Thompson, F.S. Bates, M. Dettloff, G. Jacob, N. Verghese and H. Pham. 2009. Effect of crosslink density on fracture behavior of model epoxies containing block copolymer nanoparticles. Polymer 50:4683-4689.

Liu, J., H.-J. Sue, Z.J. Thompson, F.S. Bates, M. Dettloff, G. Jacob, N. Verghese and H. Pham. 2009a. Strain rate effect on toughening of nano-sized PEP-PEO block copolymer modified epoxy. Acta Materialia 57:26912701.

Liu, J., Z.J. Thompson, H.-J. Sue, F.S. Bates, M.A. Hillmyer, M. Dettloff, G. Jacob, N. Verghese and H. Pham. 2010. Toughening of epoxies with block copolymer micelles of wormlike morphology. Macromolecules 43:7238-7243.

Ocando, C., A. Tercjak and I. Mondragon. 2010. Nanostructured systems based on SBS epoxidized triblock copolymers and well-dispersed alumina/epoxy matrix composites. Composites Science and Technology 70:1106-1112.

Pandit, R., J. Giri, G.H. Michler, R. Lach, W. Grellmann, B. Youssef, J.M. Saiter and R. Adhikari. 2012. Effect of epoxidation of diene component of SBS block copolymer on morphology and mechanical properties. Macromolecular Symposia 315:152-159.

Serrano, E., M. Larranaga, P.M. Remiro, I. Mondragon, P.M. Carrasco, J.A. Pomposo and D. Mecerreyes. 2004. Synthesis and characterization of epoxidized styrene-butadiene block copolymers as templates for nanostructured thermosets. Macromolecular Chemistry and Physics 205:987-996. 
Nepal Journal of Science and Technology Vol. 13, No. 1 (2012) 81-88

Serrano, E., A. Tercjak, G. Kortaberria, J.A. Pomposo, D. Mecerreyes, N.E. Zafeiropoulos, M. Stamm and I. Mondragon. 2006. Nanostructured thermosetting systems by modification with epoxidized styrenebutadiene star block copolymers. Effect of epoxidation degree. Macromolecules 39:2254-2261.

Serrano, E., A. Tercjak, C. Ocando, M. Larranaga, M.D.
Parellada, S.C. Galvan, D. Mecerreyes, N.E. Zafeiropoulos, M. Stamm and I. Mondragon. 2007. Curing behavior and final properties of nanostructured thermosetting systems modified with epoxidized styrene-butadiene linear diblock copolymers. Macromolecular Chemistry and Physics 208:22812292. 